\title{
Optimization of mechanochemical-assisted extraction of hesperidin from Pericarpium Citri Reticulatae
}

\author{
Tingyu JIN ${ }^{1}$, Meijing $\mathrm{YU}^{2}$, Mingxi $\mathrm{CAO}^{1}$, Xingyi ZHU ${ }^{1,2 *}$ (i)
}

\begin{abstract}
Mechanochemical-assisted extraction (MCAE) of hesperidin from Pericarpium Citri Reticulatae was investigated in AGO-2 high intensity planetary activator. In order to optimize extraction efficiency, six variables (different kinds of reagents, $\mathrm{Na}_{2} \mathrm{CO}_{3}$ content, grinding time, extraction temperature, extraction time, liquid/solid ratio) were varied. Results showed that the optimum MCAE conditions were determined as: $\mathrm{Na}_{2} \mathrm{CO}_{3}$ content of $30.0 \%(\mathrm{w} / \mathrm{w})$, grinding time $20 \mathrm{~min}$, extraction temperature $20^{\circ} \mathrm{C}$, extraction time $10 \mathrm{~min}$, liquid/solid ratio of $80: 1 \mathrm{~mL} / \mathrm{g}$. Meanwhile, enhancement of solubility was measured. Fourier transform-infrared spectrometer and scanning electron microscope were used to illustrate structure change of hesperidin after mechanochemical pretreatment. With the optimized parameter settings, MCAE with water as solvent gave the highest hesperidin yield while reducing both extraction time and energy costs compared to the heat-reflux and superfine grinding extraction.
\end{abstract}

Keywords: mechanochemistry; hesperidin; Pericarpium Citri Reticulatae; extraction.

Practical Application: Mechanochemical-assisted extraction method can be applied to extraction of hesperidin from Pericarpium Citri Reticulatae.

\section{Introduction}

Pericarpium Citri Reticulatae (PCR) has been widely used as in foods and medicines for a long time because of good activity, rich resources, low toxicity and costs (Wang et al., 2008). PCR contains significant flavonoids that are bioactive compounds with health-related properties. The most abundant flavones component in PCR is hesperidin (Figure 1) which exerts a variety of pharmacological effects such as antioxidation (Malterud \& Rydland, 2000; Vinson et al., 2002), blood lipid-lowering (Santos et al., 1999; Choe et al., 2001), anti-inflammatory activity (Manthey et al., 2001), anti-microbial activity (Bae et al., 1999) and inhibiting the vitro proliferation of cancer cells (Kohno et al., 2001). Traditional methods for extracting hesperidin from complex plant matrixes have varied from traditional solvent extraction to more modern techniques such as supercritical fluid extractions (Señoráns et al., 2001), enzyme-assisted extraction ( $\mathrm{Li}$ et al., 2006), and ultrasound-assisted extraction (Ma et al., 2008). The drawbacks of traditional technology to extract hesperidin include the use of toxic and flammable organic solvent, the low extraction yield in single treatment step, increased production losses, and environmental contamination (Korolev et al., 2003).

Mechanochemistry, studying the stress-induced structural changes which include phase transitions and chemical reactions, is an interdisciplinary science based on mechanics and chemistry (Zhang et al., 2008). For the advantages of simplifying of the process and physicochemical changes of substances in all states, mechanochemistry has been applied in formation of molecular complexes of medicinal compounds with natural polymers
(Isaev et al., 2004), synthesis of nanocomposite (Mousavi et al., 2009), and degradation of wastes (Tongamp et al., 2008). More recently, the novel application of mechanochemicalassisted extraction (MCAE) technology in vegetable materials extraction processing attracts wide attentions. For example, it has improved extraction yield of triterpene acids from fir needles by $35.9 \%$ (Korolev et al., 2003). During mechanical activation, impact-shearing on the particles of the processed material is accompanied by destruction of the cell wall. This significantly facilitates the isolation of the components in the processed material. Furthermore, the extraction time is reduced significantly because of mechanicochemical treatment increase the effective surface area of the mixture components.

In this work, MCAE was applied to extract hesperidin from PCR. The aims of this investigation were: (1) to determine the optimal extraction conditions; (2) to compare the yield of hesperidin using MCAE with that using other extraction methods; (3) to illustrate the possible mechanism of MCAE of hesperidin.

\section{Materials and methods}

\subsection{Materials}

PCR were collected from Lanxi, Zhejiang Province, China; standard hesperidin (Chinese Medical and Biological Products Institute, Beijing, China); analytical-grade reagents (Tianjin Siyou Biomedical Technology Co., Ltd., Tianjin, China); methanol 
and phosphoric acid (Chinese Medical and Biological Products Institute, Beijing, China). Distilled water was used for all the extractions.

\subsection{Chromatographic analysis}

HPLC analysis of hesperidin was performed on an Agilent 1100 HPLC chromatograph. The analysis was carried out using analytical column Waters XTeert $\mathrm{C}_{18}$ column $\left(4.6^{\star} 150 \mathrm{~mm}\right)$. The mobile phase consisted of two solvents: $0.1 \%$ phosphoric acid (A) and 100\% methanol (B). The solvent gradient in volume ratios was as follows: $25 \%$ B for $15 \mathrm{~min}$; $25 \%$ to $33 \%$ B from 15 to $22 \mathrm{~min}$; then it was maintained at $33 \% \mathrm{~B}$. The column temperature was $25^{\circ} \mathrm{C}$, sample volume injected was $20 \mu \mathrm{L}$ and the flow rate was $1 \mathrm{~mL} / \mathrm{min}$. The optimum detecting wavelength for hesperidin was $286 \mathrm{~nm}$. Under above conditions hesperidin

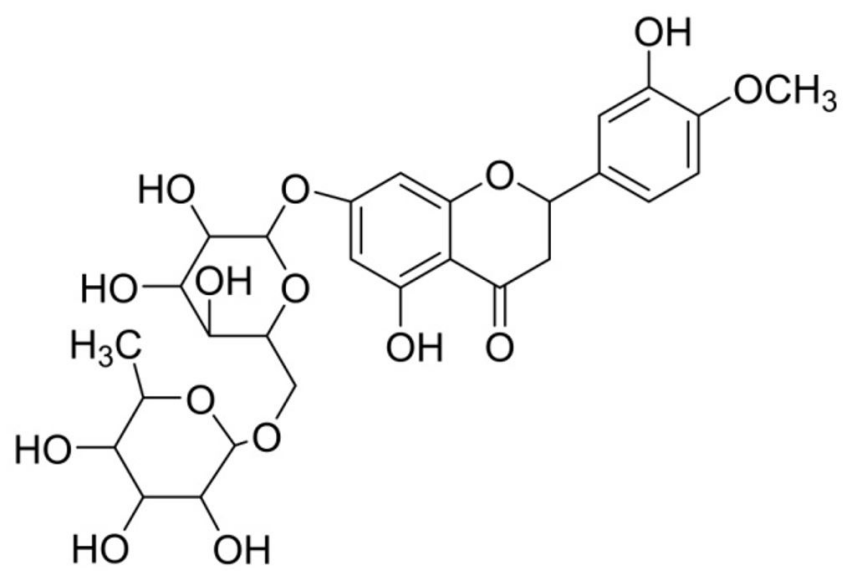

Figure 1. Molecular structure of hesperidin. gave a peak at $29.8 \mathrm{~min}$. Figure 2 shows the HPLC chromatograph of standard hesperidin and the hesperidin extract obtained by MCAE. All hesperidin extract obtained were filtered through $0.45 \mu \mathrm{m}$ membrane. Analyses were performed at least three times and only mean values were reported.

\subsection{MCAE procedure}

The mechanochemical activation of raw plant material of PCR was carried out in AGO-2 mill in the presence of $\mathrm{Na}_{2} \mathrm{CO}_{3}$ at room temperature. After milling, the samples changed into fine powder (Particle diameter size: $\mathrm{D}_{90} \leq 50 \mu \mathrm{m}$ ), then they were loaded into glassing flask with an electric stirrer, followed by adding water as extraction solvent. After stirring for $20 \mathrm{~min}$ at room temperature, and then centrifuging at $4700 \mathrm{rpm}$ for $10 \mathrm{~min}$, the supernatant was acidified to $\mathrm{pH} 4.0$ and then analyzed by HPLC.

\subsection{Superfine milling extraction procedure}

The superfine milling of raw plant material of PCR was carried out in AGO-2 mill to obtain fine powder (Particle diameter size: $\left.\mathrm{D}_{90} \leq 50 \mu \mathrm{m}\right)$. The grounded powder of $5.0 \mathrm{~g}$ and the solvent ( $75 \%$ aqueous ethanol) were loaded into glassing flask with an electric stirrer. The extraction was performed at $80^{\circ} \mathrm{C}$ for 2 hours and then centrifuged at $4700 \mathrm{rpm}$ for $10 \mathrm{~min}$. The supernatants were filtered through a $0.45 \mu \mathrm{m}$ membrane filter and analyzed directly by HPLC.

\subsection{Heat reflux extraction procedure}

The ground powder of $5.0 \mathrm{~g}$ and the solvent ( $75 \%$ aqueous ethanol) were loaded into glassing flask with an electric stirrer. The extraction was performed at $80{ }^{\circ} \mathrm{C}$ for 2 hours and then centrifuged at $4700 \mathrm{rpm}$ for $10 \mathrm{~min}$. The supernatants were filtered through a $0.45 \mu \mathrm{m}$ membrane filter and analyzed directly by HPLC.

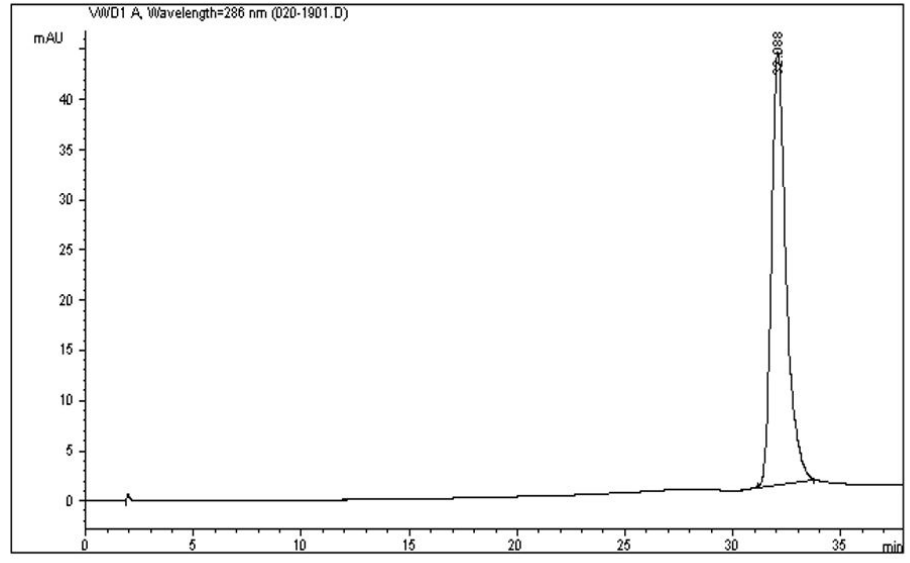

a

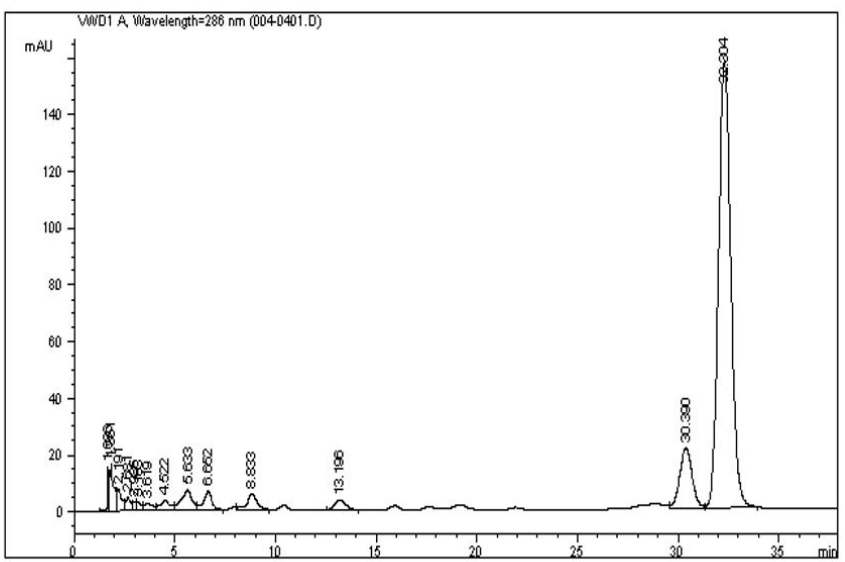

b

Figure 2. HPLC chromatograph of standard hesperidin (a); HPLC chromatograph of hesperidin extract obtained by MCAE (b). 


\subsection{Scanning electron microscopy (SEM)}

Structural of the samples were examined by scanning electron microscopy (SEM): Hitachi S-4700, which was bought from Hitachi (Tokyo, Japan). Prior to observation, the membranes were broken in liquid nitrogen, fixed on adhesive tape and then coated with gold films.

\subsection{Fourier Transform Infrared Spectroscopy (FTIR)}

The IR spectra were analyzed by FT-IR-8200 spectrometer (Shimadzu, Kyoto, Japan) to identify the structure change of hesperidin before and after mechanochemical pretreatment. $2 \mathrm{mg}$ samples and $200 \mathrm{mg}$ potassium bromide were mixed in a tablet and then analyzed in the range of $4000-400 \mathrm{~cm}^{-1}$ with a resolution of $4 \mathrm{~cm}^{-1}$.

\subsection{Statistical analysis}

Statistical analysis was performed using OriginPro 8.0 SR3 for Windows. All values were expressed as their mean \pm standard deviation (SD), and levels of significance were evaluated using one-way ANOVA with the Student-Neuman-Keuls (SNK) test for multiple comparison. The differences were considered significant at the level of $\mathrm{p}<0.05$.

\section{Results and discussion}

\subsection{Influence of alkali reagents on extraction yield}

The alkali reagents played a vital important role in MCAE. The mechanical activation of pulverized raw plant material and reagents could change the hydrophobic character of hesperidin. After mechanical activation, the structure of hesperidin changed and became easily to solve in water. Five different kinds of alkali reagents were investigated, including $\mathrm{Ca}(\mathrm{OH})_{2}, \mathrm{NaHCO}_{3}$, $\mathrm{KHCO}_{3}, \mathrm{Na}_{2} \mathrm{CO}_{3}, \mathrm{~K}_{2} \mathrm{CO}_{3}$ (Figure 3). The results showed that $\mathrm{Na}_{2} \mathrm{CO}_{3}$ exhibited the highest extraction yield $(\mathrm{p}<0.05)$ under the same extraction condition, which will form an insoluble chelate of calcium with hesperidin after mechanical activation. The alkality of $\mathrm{NaHCO}_{3}, \mathrm{KHCO}_{3}$ were too weak to react with hesperidin completely. The alkality of $\mathrm{K}_{2} \mathrm{CO}_{3}$ was too strong and during the mechanical activation, part of hesperidin will be decomposed. Compared with other alkalis, $\mathrm{Na}_{2} \mathrm{CO}_{3}$ was selected as an optimum alkali reagent for our extraction experiments.

\subsection{Influence of $\mathrm{Na2CO} 3$ content on extraction yield}

Minimal reagent content for MCAE of PCR material was investigated at $\mathrm{Na}_{2} \mathrm{CO}_{3}$ concentrations of 10.0, 20.0, 30.0, 40.0, 50.0 , and $60.0 \%(\mathrm{w} / \mathrm{w})$. Hesperidin yield increased $(p<0.05)$ from $4.07 \%$ with $\mathrm{Na}_{2} \mathrm{CO}_{3}$ content of $10.0 \%$ to $5.16 \%$ with $\mathrm{Na}_{2} \mathrm{CO}_{3}$ at $30.0 \%$ and reached the highest yield with $\mathrm{Na}_{2} \mathrm{CO}_{3}$ at $30.0 \%$, and then hesperidin yield gradually decreased (Figure 4). The reason for hesperidin yield declined when $\mathrm{Na}_{2} \mathrm{CO}_{3}$ content over $30.0 \%$ might be related to excess of alkali could decompose hesperidin under grinding condition. For these observations, $\mathrm{Na}_{2} \mathrm{CO}_{3}$ content of $30.0 \%$ was optimal for MCAE of hesperidin from PCR.

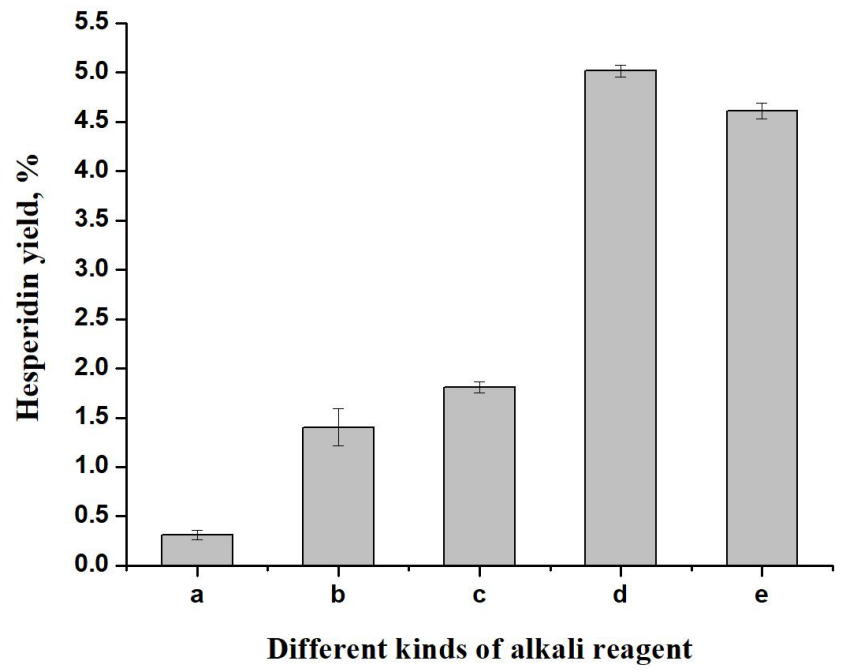

Figure 3. Influence of different kinds of alkali reagent on the extraction of hesperidin by MCAE. Data were presented as mean \pm SD $(n=3)$. Means with different letters were significantly different $(p<0.05)$.

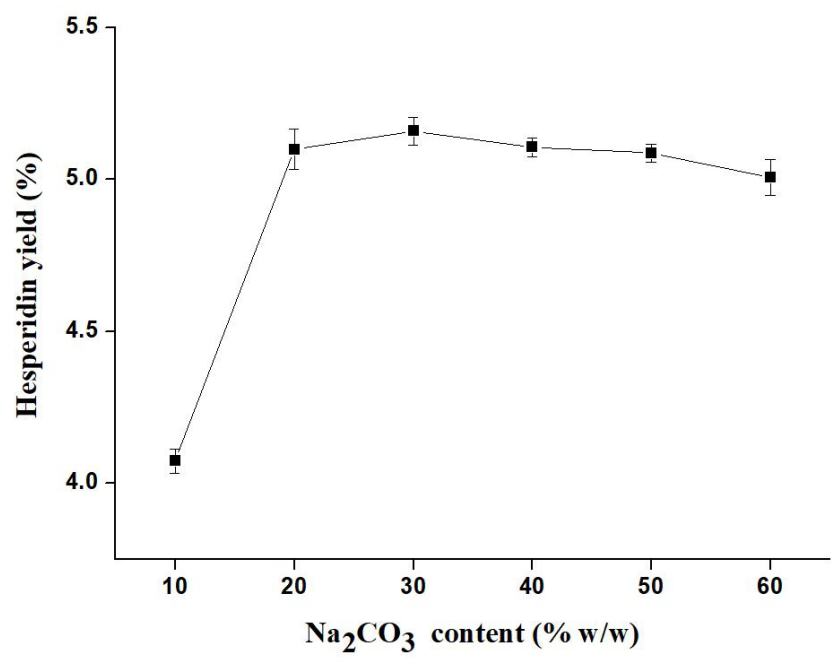

Figure 4. Influence of $\mathrm{Na}_{2} \mathrm{CO}_{3}$ content on the extraction of hesperidin by MCAE. Data were presented as mean \pm SD $(n=3)$. Means with different letters were significantly different $(\mathrm{p}<0.05)$.

\subsection{Influence of grinding time on extraction yield}

Owing to the importance of grinding time for hesperidin yield, further study on the influence of grinding time was investigated. From Figure 5, it was found that hesperidin yield increased from $2.79 \%$ to $5.20 \%$ with the grinding time increasing from $2.5 \mathrm{~min}$ to $20 \mathrm{~min}$. Then the yield of hespridin remained steadily $(\mathrm{p}<0.05)$ with grinding time increased from $20 \mathrm{~min}$ to $30 \mathrm{~min}$. These results revealed that the mechanochemical pretreatment was accompanied by not only structure change of target compounds but also destruction of the cell covering and wall which increased the contact surface area between the plant matrix and the solvent. But with the further increasing 


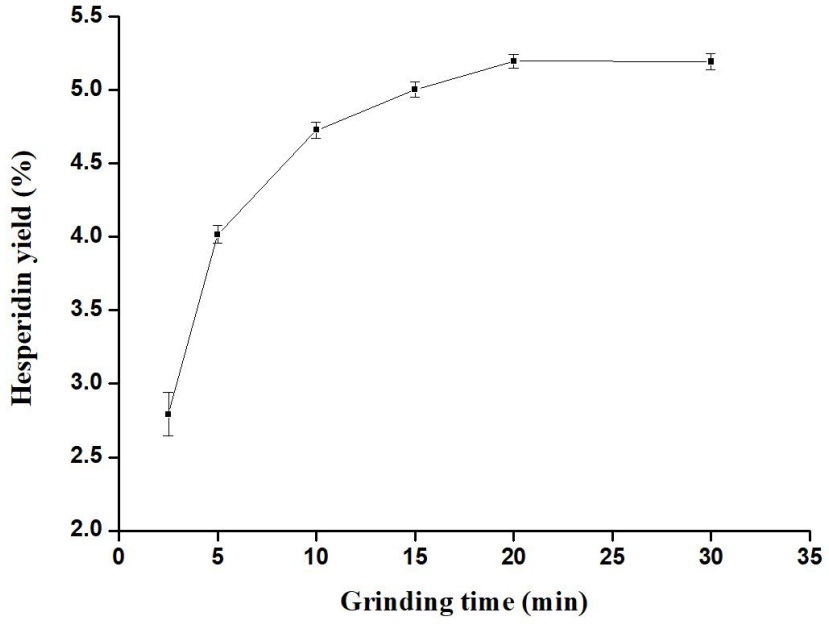

Figure 5. Influence of grinding time on the extraction of hesperidin by MCAE. Data were presented as mean $\pm \operatorname{SD}(n=3)$. Means with different letters were significantly different $(\mathrm{p}<0.05)$.

grinding time hesperidin might decompose, this offset the raise of hesperidin yield due to the increasing of contact surface area between the plant matrix and the solvent. Thus, $20 \mathrm{~min}$ of extraction time was selected as the standard condition for MCAE of hesperidin from PCR.

\subsection{Influence of extraction temperature on extraction yield}

As could be seen from Figure 6, the yield of hesperidin was dropped $(\mathrm{p}<0.05)$ from $5.13 \%$ to $4.15 \%$ as the rise of the temperature from $20^{\circ} \mathrm{C}$ to $80^{\circ} \mathrm{C}$. These results reflected that the high temperature was not beneficial for MCAE due to hesperidin sensitive to alkali and high temperature. Thus, for the purpose of raising yield of hesperidin and saving extraction cost, room temperature $\left(20^{\circ} \mathrm{C}\right)$ was select as the standard extraction temperature.

\subsection{Influence of extraction time on extraction yield}

The influence of the extraction time from 2 to $30 \mathrm{~min}$ was investigated (Figure 7). The results showed the yield of hesperidin increased $(\mathrm{p}<0.05)$ from $5.18 \%$ to $5.26 \%$ with extraction time from 2 to $10 \mathrm{~min}$. This reflected the mechanochemical pretreatment had broken the cell and strongly eliminate hinder of internal cell contents to dissolve in extraction solvent. However, the yield of hesperidin decreased slowly $(\mathrm{p}<0.05)$ from $5.26 \%$ to $5.10 \%$ with extraction time from 10 to $30 \mathrm{~min}$, which might attribute to the slowly degradation of hesperidin under the alkali condition. Considering to save extraction time and to get highest yield, 10 min was select as the standard extraction time.

\subsection{Influence of Liquid/Solid ratio $(\mathrm{mL} / \mathrm{g})$ on extraction yield}

The influence of liquid/solid ratio in the MCAE process was investigated ranging from 10:1 to $100: 1 \mathrm{~mL} / \mathrm{g}$ (Figure 8). These results showed that the yield of hesperidin increased $(p<0.05)$

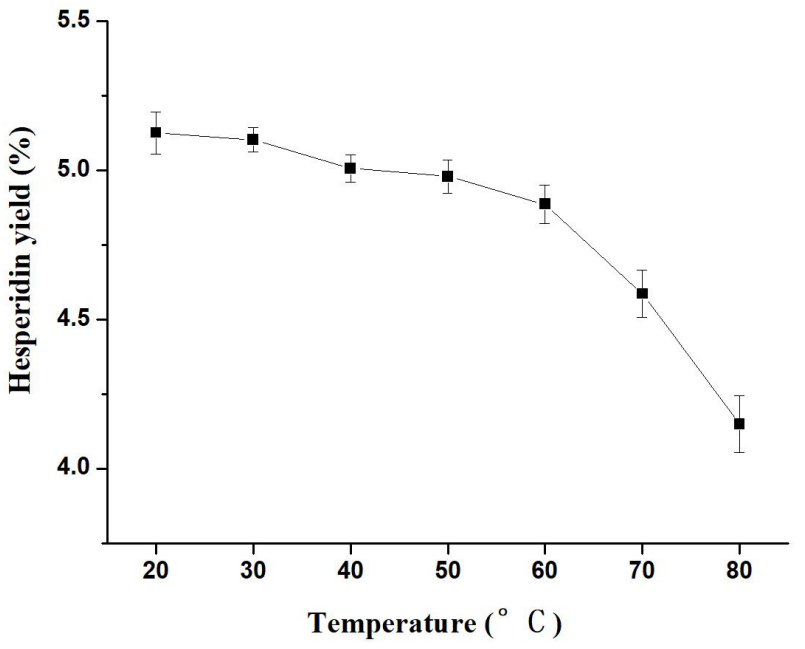

Figure 6. Influence of extraction temperature on the extraction of hesperidin by MCAE. Data were presented as mean $\pm \mathrm{SD}(\mathrm{n}=3)$. Means with different letters were significantly different $(p<0.05)$.

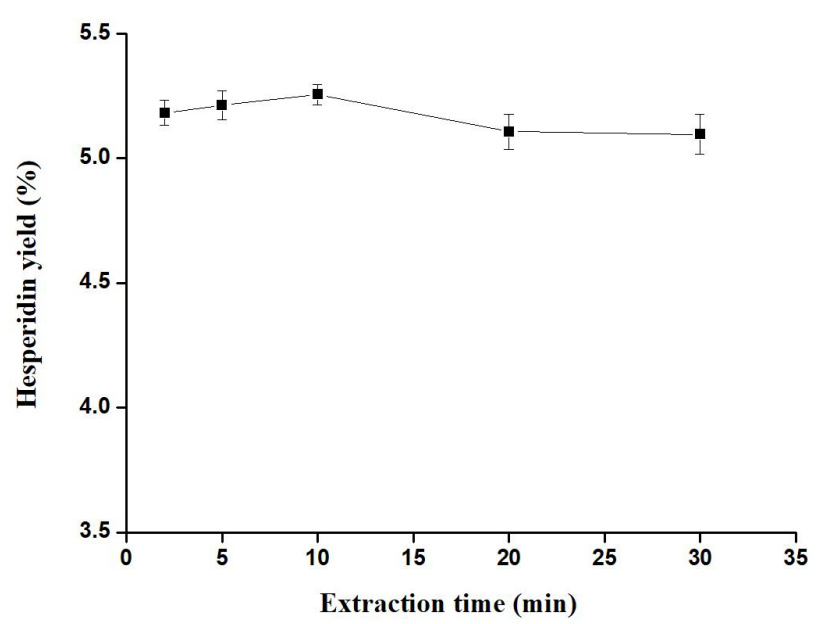

Figure 7. Influence of extraction time on the extraction of hesperidin by MCAE. Data were presented as mean \pm SD $(n=3)$. Means with different letters were significantly different $(\mathrm{p}<0.05)$.

from $3.15 \%$ to $5.64 \%$ with liquid/solid ratio increased from $10: 1$ to $80: 1 \mathrm{~mL} / \mathrm{g}$ and then remained steadily $(\mathrm{p}<0.05)$ when liquid/solid ratio was 100:1 mL/g. Target compounds could fully solve in larger volume of solvent, the increased of the yield of hesperidin might attribute to the larger volume of extraction solvent. When liquid/solid ratio arrived at 100:1, hesperidin was fully solved in solvent, thus the yield remained steadily. Therefore, liquid/solid ratio $100: 1 \mathrm{~mL} / \mathrm{g}$ was selected as the standard condition for this MCAE.

\subsection{Comparing MCAE with Heat-Reflux and Superfine Grinding Extraction}

The results of yield of hesperidin extracted with different methods were shown in Table 1. Superfine grinding produced comparable yield of hesperidin (5.13\% vs. $4.65 \%)$ to traditional 
heat-reflux extraction but without reducing extraction time. The MCAE process defined in this study increased $(p<0.05)$ the hesperidin yield by an average of $10.2 \%$ over superfine grinding, with water as solvent, rather than ethanol, and extraction time reduced from $3 \mathrm{~h}$ to $10 \mathrm{~min}$, compared with superfine grinding and heat-reflux extraction. These results indicated that MCAE could greatly reduce extraction time, raise extraction yield and asking for water as only extraction solvent.

\subsection{Solubility test of hesperidin}

The hydrophobic character of hesperidin was the most critical factor limiting the dissolve procedure of hesperidin in water (Kanaze et al., 2006). So an enhancement of dissolution

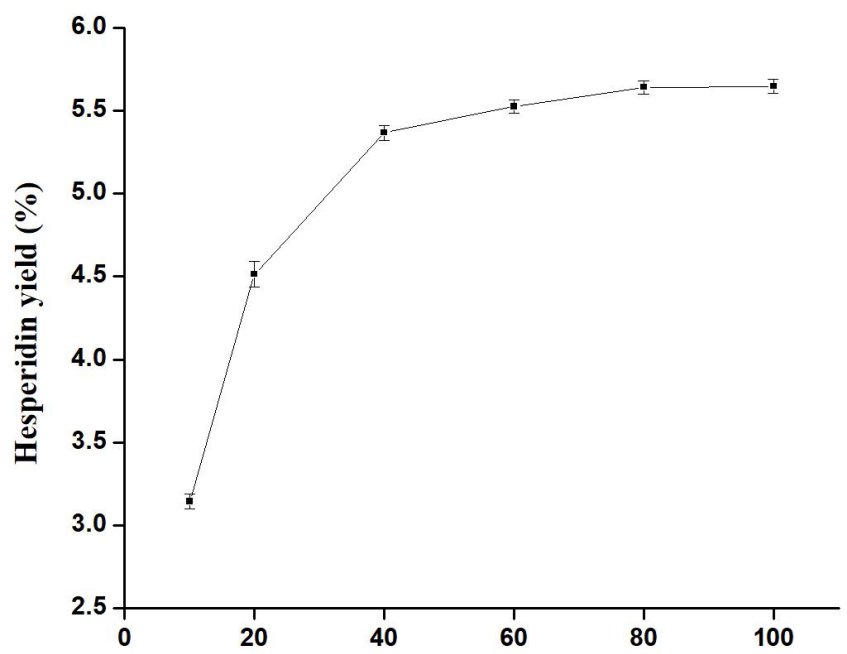

Liquid/solid ratio $(\mathrm{mL} / \mathrm{g})$

Figure 8. Influence of liquid/solid ratio on the extraction of hesperidin by MCAE. Data were presented as mean $\pm S D(n=3)$. Means with different letters were significantly different $(\mathrm{p}<0.05)$. rate of hesperidin in water could significantly increase the extraction rate and yield of hesperidin when using water as extraction solvent. As shown in Table 2, three processes were compared. The solubility of hesperidin after mechanochemical pretreatment significantly increased $(\mathrm{p}<0.05)$ by an average of $30.0 \%$ over grinding hesperidin mixed with $\mathrm{Na}_{2} \mathrm{CO}_{3}$ and about 15 time more than grinding hesperidin directly solved in water. Thus, mechanochemical pretreatment played an important role in enhancing solubility of hesperidin in water.

\subsection{Changes of physical structural after pretreatment}

Mechanochemical pretreatments could destroy the physical structures of the plant cells by destructing cell wall, SEM was used to examine the effect of it. Pulverized raw material samples (Figure 9a), which the primary structures were unaffected, showed puny damage cells and coarse surface of samples. From both of the Figure $9 \mathrm{~b}$ and Figure 9c, typical destruction of cells and obvious disruption on the surface of samples were observed, indicating a possibly complete breakup of the cell wall after the mechanical activation (Yang \& Zhang, 2008). The results exhibited that the structure of cells of PCR could be destroyed efficiently after mechanical or mechanochemical pretreatment. Thus, the cell contents could be easily released into the extraction solution should attribute to the effect of mechanochemical pretreatment.

\subsection{Changes of chemical structural after pretreatment}

FTIR spectrum of hesperidin (a) and hesperidin after mechanochemical pretreatment with $\mathrm{Na}_{2} \mathrm{CO}_{3}$ (b) were compared in Fig 10. From Figure 10a, it could be seen that stretching vibration absorbance peak of hydroxyl group and carbonyl group were found at $3469 \mathrm{~cm}^{-1}$ and $1650 \mathrm{~cm}^{-1}$ respectively (Song et al., 2009). In addition, stretching vibration peaks of cyclobenzene skeleton in the hesperidin was found from 1600 to $1400 \mathrm{~cm}^{-1}$. However, as shown in Figure 10b, many tiny peaks from 1600 to $1400 \mathrm{~cm}^{-1}$ disappeared in the spectrum of hesperidin after mechanochemical pretreatment with $\mathrm{Na}_{2} \mathrm{CO}_{3}$, while the intensity of the band relative to the carboxylic group decreased. This

Table 1. Comparing MCAE with heat-reflux and superfine grinding extraction.

\begin{tabular}{cccc}
\hline & MCAE & Superfine grinding extraction & Heat-reflux extraction \\
\hline Pretreatment & MCAE & M & CON \\
Extraction procedure & Stirring & Heat-reflux & Heat-reflux \\
Extraction time & $10 \mathrm{~min}$ & 3 hour & 3 hour \\
Solvent & water & Aqueous ethanol & Aqueous ethanol \\
Liquid/solid ratio & $80: 1 \mathrm{~mL} / \mathrm{g}$ & $80: 1 \mathrm{~mL} / \mathrm{g}$ & $80: 1 \mathrm{~mL} / \mathrm{g}$ \\
Hesperidin yield $(\%)$ & $5.65 \pm 0.01$ & $5.127 \pm 0.025$ & $4.647 \pm 0.012$ \\
\hline
\end{tabular}

Data were presented as mean \pm SD $(n=3)$. Means of hesperidin yield without the same letters were significantly different $(\mathrm{p}<0.05)$.

Table 2. Comparing solubility of hesperidin in water treated with different methods.

\begin{tabular}{cccc}
\hline Sample & \multirow{2}{*}{ Grinded hesperidin } & Grinded hesperidin mixed with & Hesperidin grind with $\mathrm{Na}_{2} \mathrm{CO}_{3}$ \\
\hline Solvent & Water & Water & Water \\
Concentration $(\mathrm{mg} / \mathrm{L})$ & $4.85 \pm 0.02$ & $59.28 \pm 0.31$ & $77.15 \pm 0.46$ \\
\hline
\end{tabular}




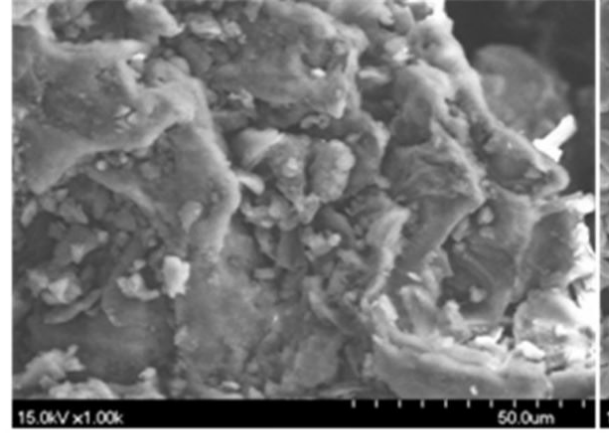

a

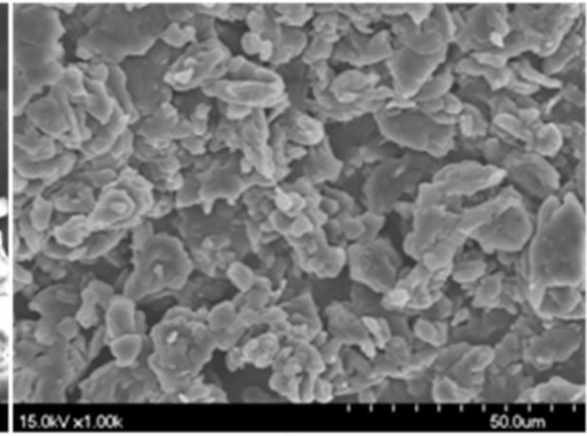

b

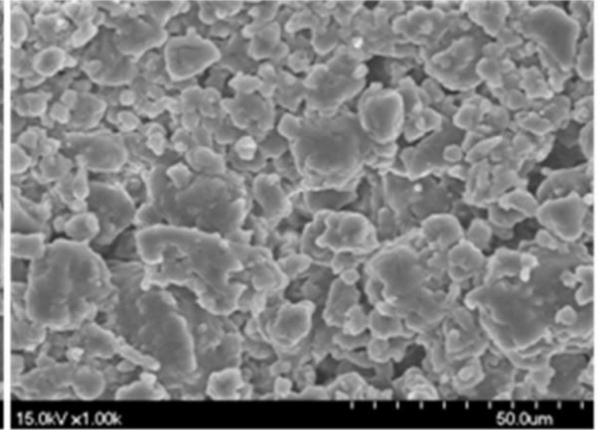

C

Figure 9. SEM micrographs of PCR treated with different procedures: (a) pulverized PCR powder; (b) pulverized PCR powder grinding for 20 min without $\mathrm{Na}_{2} \mathrm{CO}_{3}$; (c) pulverized PCR powder grinding for 20 min with $\mathrm{Na}_{2} \mathrm{CO}_{3}$ content of $30 \%$.

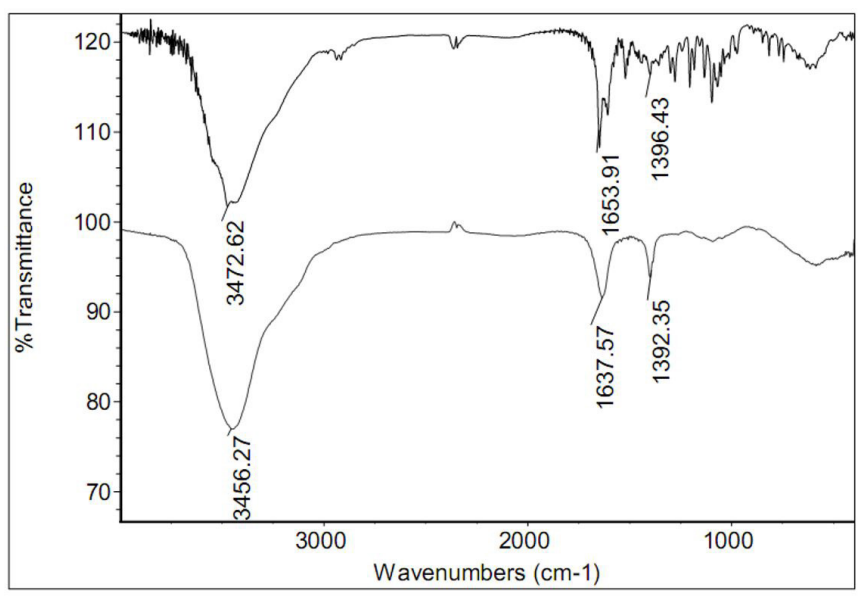

Figure 10. FTIR spectra of hesperidin (a), FTIR spectra of hesperidin after mechanochemical pretreatment with $\mathrm{Na}_{2} \mathrm{CO}_{3}$ (b).

phenomenon indicated that the chemical structural of hesperidin changed during mechanochemical pretreatment process.

\section{Conclusion}

MCAE is a novel method used to extract hesperidin from PCR. The effects of parameters on the efficiency of MCAE for the hesperidin extraction are studied and optimized. Optimal extraction is obtained by using superfine powdered plant material $\left(\mathrm{D}_{90}<50 \mu \mathrm{m}\right)$ with $\mathrm{Na}_{2} \mathrm{CO}_{3}$ content of $30 \%(\mathrm{w} / \mathrm{w})$, extracted with water (liquid/solid ratio of $80: 1, \mathrm{~mL} / \mathrm{g}$ ) for $10 \mathrm{~min}$ at $20{ }^{\circ} \mathrm{C}$. Mechanochemical pretreatment can change physical and chemical structural of hesperidin and enhance the solubility of hesperidin. Therefore, compared with conventional extraction methods, MCAE has excellent advantages, such as shorter extraction time, higher yield and lower energy consumption. Moreover, the favorable solvent is water, thus MACE can be called an 'environment-friendly' or 'green' technique. Overall, MCAE of hesperidin from PCR by only using water as extraction solvent has a strong potential of industrial development as an efficient and environment-friendly process.

\section{Conflict of interest}

The authors declare that there is no conflict of interest.

\section{Acknowledgments}

This work was supported by the Basic Public Welfare Research Project of Zhejiang Province (No. LGF20H300011).

\section{References}

Bae, E. A., Han, M. J., \& Kim, D. H. (1999). In vitro anti-Helicobacter pylori activity of some flavonoids and their metabolites. Planta Medica, 65(5), 442-443. http://dx.doi.org/10.1055/s-2006-960805. PMid:10454900.

Choe, S. C., Kim, H. S., Jeong, T. S., Bok, S. H., \& Park, Y. B. (2001). Naringin has an antiatherogenic effect with the inhibition of intercellular adhesion molecule- 1 in hypercholesterolemic rabbits. Journal of Cardiovascular Pharmacology, 38(6), 947-955. http:// dx.doi.org/10.1097/00005344-200112000-00017. PMid:11707699.

Isaev, A. A., Lomovskii, O. I., Koralev, K. G., \& Karimov, R. K. (2004). Mechanochemical modification of 5-nitro-8-hydroxyquinoline with cellulose, pectin, and $\beta$-cyclodextrin. Chemistry of Natural Compounds, 40(3), 266-268. http://dx.doi.org/10.1023/B:CONC.0000039138.54635.71.

Kanaze, F. I., Kokkalou, E., Niopas, I., Georgarakis, M., Stergiou, A., \& Bikiaris, D. (2006). Thermal analysis study of flavonoid solid dispersions having enhanced solubility. Journal of Thermal Analysis and Calorimetry, 83(2), 283-290. http://dx.doi.org/10.1007/s10973005-6989-9.

Kohno, H., Taima, M., Sumida, T., Azuma, Y., Ogawa, H., \& Tanaka, T. (2001). Inhibitory effect of mandarin juice rich in beta-cryptoxanthin and hesperidin on 4-(methylnitrosamino)-1-(3-pyridyl)-1-butanoneinduced pulmonary tumorigenesis in mice. Cancer Letters, 174(2), 141-150. http://dx.doi.org/10.1016/S0304-3835(01)00713-3. PMid:11689289.

Korolev, K. G., Lomovskii, O. I., Rozhanskaya, O. A., \& Vasil'ev, V. G. (2003). Mechanochemical preparation of water-soluble forms of triterpene acids. Chemistry of Natural Compounds, 39(4), 366-372. http://dx.doi.org/10.1023/B:CONC.0000003418.28517.f6.

Li, B. B., Smith, A. B., \& Hossain, M. M. (2006). Extraction of phenolics from citrus peels II. Enzyme-assisted extraction method. Separation and Purification Technology, 48(2), 189-196. http://dx.doi.org/10.1016/j. seppur.2005.07.019. 
Ma, Y. Q., Ye, X. Q., Hao, Y. B., Xu, G. N., Xu, G. H., \& Liu, D. H. (2008). Ultrasound-assisted extraction of hesperidin from Penggan (Citrus reticulata) peel. Ultrasonics Sonochemistry, 15(3), 227-232. http:// dx.doi.org/10.1016/j.ultsonch.2007.03.006. PMid:17584518.

Malterud, K. E., \& Rydland, K. M. (2000). Inhibitors of 15-Lipoxygenase from Orange Peel. Journal of Agricultural and Food Chemistry, 48(11), 5576-5580. http://dx.doi.org/10.1021/jf000613v. PMid:11087521.

Manthey, J. A., Grohmann, K., \& Guthrie, N. (2001). Biological properties of citrus flavonoids pertaining to cancer and inflammation. Current Medicinal Chemistry, 8(2), 135-153. http://dx.doi. org/10.2174/0929867013373723. PMid:11172671.

Mousavi, T., Karimzadeh, F., \& Abbasi, M. H. (2009). Mechanochemical assisted synthesis of NiTi intermetallic based nanocomposite reinforced by Al2O3. Journal of Alloys and Compounds, 467(1-2), 173-178. http://dx.doi.org/10.1016/j.jallcom.2007.11.136.

Santos, K. F., Oliveira, T. T., Nagem, T. J., Pinto, A. S., \& Oliveira, M. G. (1999). Hypolipidaemic effects of naringenin, rutin, nicotinic acid and their associations. Pharmacological Research, 40(6), 493-496. http://dx.doi.org/10.1006/phrs.1999.0556. PMid:10660947.

Señoráns, F. J., Ruiz-Rodriguez, A., Cavero, S., Cifuentes, A., Ibanez, E., \& Reglero, G. (2001). Isolation of antioxidant compounds from orange juice by using countercurrent supercritical fluid extraction (CC-SFE). Journal of Agricultural and Food Chemistry, 49(12), 6039-6044. http://dx.doi.org/10.1021/jf010762t. PMid:11743805.

Song, X. L., Li, J. H., Wang, J. T., \& Chen, L. X. (2009). Quercetin molecularly imprinted polymers: Preparation, recognition characteristics and properties as sorbent for solid-phase extraction. Talanta, 80(2), 694702. http://dx.doi.org/10.1016/j.talanta.2009.07.051. PMid:19836539.

Tongamp, W., Kano, J., Zhang, Q., \& Saito, F. (2008). Simultaneous treatment of PVC and oyster-shell wastes by mechanochemical means. Waste Management, 28(3), 484-488. http://dx.doi.org/10.1016/j. wasman.2007.01.022. PMid:17475466.

Vinson, J. A., Liang, X. Q., Proch, J., Hontz, B. A., Dancel, J., \& Sandone, N. (2002). Polyphenol antioxidants in citrus juices: In vitro and in vivo studies relevant to heart disease. Advances in Experimental Medicine and Biology, 505, 113-122. http://dx.doi.org/10.1007/9781-4757-5235-9_10. PMid:12083455.

Wang, Y. M., Yi, L. Z., Liang, Y. Z., Li, H. D., Yuan, D. L., Gao, H. Y., \& Zeng, M. M. (2008). Comparative analysis of essential oil components in Pericarpium Citri Reticulatae Viride and Pericarpium Citri Reticulatae by GC-MS combined with chemometric resolution method. Journal of Pharmaceutical and Biomedical Analysis, 46(1), 66-74. http://dx.doi.org/10.1016/j.jpba.2007.08.030. PMid:17942260.

Yang, Y., \& Zhang, F. (2008). Ultrasound-assisted extraction of rutin and quercetin from Euonymus alatus (Thunb.) Sieb. Ultrasonics Sonochemistry, 15(4), 308-313. http://dx.doi.org/10.1016/j. ultsonch.2007.05.001. PMid:17606398.

Zhang, W., Zhang, X. X., Liang, M., \& Lu, C. H. (2008). Mechanochemical preparation of surface-acetylated cellulose powder to enhance mechanical properties of cellulose-filler-reinforced NR vulcanizates. Composites Science and Technology, 68(12), 2479-2484. http://dx.doi. org/10.1016/j.compscitech.2008.05.005. 